\title{
Development of composite steam electrodes for electrolysers based on barium zirconate
}

\author{
Nuria Bausá ${ }^{1}$, Cecilia Solís ${ }^{1}$, Ragnar Strandbakke ${ }^{2}$, José M. Serra ${ }^{1, *}$ \\ 1: Instituto de Tecnología Química (Universidad Politécnica de Valencia - Consejo \\ Superior de Investigaciones Científicas), Av. Naranjos s/n, E-46022 Valencia (SPAIN) \\ 2: Department of Chemistry, University of Oslo, FERMiO, Gaustadalléen 21, NO-0349 \\ Oslo, Norway. \\ * to whom correspondence should be addressed, Fax 0034.963.877.809 \\ e-mail: jmserra@itq.upv.es
}

\begin{abstract}
:
$\mathrm{La}_{0.6} \mathrm{Sr}_{0.4} \mathrm{Co}_{0.2} \mathrm{Fe}_{0.8} \mathrm{O}_{3-\delta} \quad(\mathrm{LSCF}), \quad \mathrm{La}_{2} \mathrm{NiO}_{4+\delta} \quad(\mathrm{LNO}), \quad \mathrm{La}_{0.87} \mathrm{Sr}_{0.13} \mathrm{CrO}_{4} \quad$ (LSC), $\mathrm{La}_{0.8} \mathrm{Sr}_{0.2} \mathrm{MnO}_{3-\delta} \quad$ (LSM) and $\mathrm{Ba}_{0.5} \mathrm{Sr}_{0.5} \mathrm{Co}_{0.8} \mathrm{Fe}_{0.2} \mathrm{O}_{3-\delta} \quad$ (BSCF) composite anodes deposited on proton-conducting $\mathrm{BaCe}_{0.2} \mathrm{Zr}_{0.7} \mathrm{Y}_{0.1} \mathrm{O}_{3-\delta}$ (BCZY27) electrolytes were studied as steam electrolysis anodes in symmetric cells. The effect of the electrode composition and microstructure on the electrochemical behavior was investigated using impedance spectroscopy in the $800-500{ }^{\circ} \mathrm{C}$ range under 3 bar of pressure of wet air (75\% of steam). The first screening revealed that 50-50 (vol.\%) LSCF/BCZY27 composite anodes show the best performance, reaching polarization resistances $<0.68$ $\Omega \cdot \mathrm{cm}^{2}$ at $700{ }^{\circ} \mathrm{C}$ and high steam pressure $(0.75$ bar of air and 2.25 bar of steam). The performance of the LSCF/BCZY27 composite was further improved by changing the ratio of the different phases. Finally the anode operation conditions (steam, oxygen and total pressures) were systematically varied in order to identify and characterize the different electrochemical processes that take place in the anode under realistic operation.
\end{abstract}

\section{KEYWORDS:}

PCEC; high steam pressure; proton conductor; anode; LSCF; composite 


\section{Introduction}

Proton conducting ceramics have attracted much interest due to their applications in energy conversion, as protonic conducting -solid oxide- fuel cells (PCFC), electrolysers (PCEC), hydrogen sensing, hydrogen separation and chemicals synthesis.[1-6] Among all the protonic conducting ceramics barium cerates and zirconates have demonstrate promising properties.[7] Barium cerates based materials show the highest protonic conductivity values, but they are unstable under $\mathrm{CO}_{2}$ containing atmospheres, which restricts their practical application. Barium zirconates based compounds are more stable, but present a much lower protonic conductivity due to the high grain boundary resistivity.[8] In order to find the optimal mix between chemical stability and proton conductivity, $\mathrm{BaCe}_{1-\mathrm{x}-\mathrm{y}} \mathrm{Zr}_{\mathrm{x}} \mathrm{Y}_{\mathrm{y}} \mathrm{O}_{3-\delta}(\mathrm{BCZY})$ materials have been proposed as proton conducting electrolytes, although they present lower protonic conductivity compared to the cerates. The search for new steam- or air electrode materials compatible with BCZY for PCEC operation is challenging since the electrode should exhibit (i) tailored electronic and ionic (protonic and oxygen-ion) conductivity, (ii) proper microstructure for fast gas exchange, and (iii) thermo-chemical stability in air and high-steam gas environments at high temperature.

High temperature electrolysis (HTE) of steam offers high efficiency of conversion of renewable and peak electricity into hydrogen[9, 10]. In solid oxide electrolysers (SOECs)[11, 12], that use oxide ion conducting electrolytes and operate at around 800 ${ }^{\circ} \mathrm{C}$, hydrogen is produced on the steam feed side (nickel-based electrode). As a consequence, SOECs present two drawbacks, i.e., the production of very humid hydrogen and the risk of oxidation of the metallic electrode at high-steam concentrations. On the other hand, in proton conducting electrolysers (PCECs)[13-15] a high temperature proton conducting electrolyte is used instead and protons are pumped and form dry $\mathrm{H}_{2}$, leaving $\mathrm{O}_{2}$ on the steam side. These PCECs can produce pressurised dry $\mathrm{H}_{2}$ directly on the cathode (nickel-based electrode). In PCECs, steam is fed in the air/oxygen electrode (anode), typically made of mixed ionic-electronic conducting ceramics.

In the present work, different materials have been proposed as electrodes for BCZY based PCECs, comprising mixed ionic-electronic conductors as $\mathrm{La}_{0.6} \mathrm{Sr}_{0.4} \mathrm{Co}_{0.2} \mathrm{Fe}_{0.8} \mathrm{O}_{3-\delta}$ (LSCF) $[16,17]$ and $\mathrm{Ba}_{0.5} \mathrm{Sr}_{0.5} \mathrm{Co}_{0.8} \mathrm{Fe}_{0.2} \mathrm{O}_{3-\delta}$ (BSCF)[17] and various $\mathrm{LaMO}_{\mathrm{x}}$ materials 


\section{Experimental}

$\mathrm{BaCe}_{0.2} \mathrm{Zr}_{0.7} \mathrm{Y}_{0.1} \mathrm{O}_{3-\delta}(\mathrm{BCZY} 27)$ powder (CerpoTech) was calcined at $1100{ }^{\circ} \mathrm{C}$ for $6 \mathrm{~h}$ and ball-milled for $10 \mathrm{~h}$ in acetone. $\mathrm{Ba}_{0.5} \mathrm{Sr}_{0.5} \mathrm{Co}_{0.8} \mathrm{Fe}_{0.2} \mathrm{O}_{3-\delta}(\mathrm{BSCF})$ was provided by IKTS Fraunhofer, $\mathrm{La}_{2} \mathrm{NiO}_{4+\delta}$ (LNO) by CerpoTech, $\mathrm{La}_{0.87} \mathrm{Sr}_{0.13} \mathrm{CrO}_{4}$ (LSC) by Praxair and $\mathrm{La}_{0.8} \mathrm{Sr}_{0.2} \mathrm{MnO}_{3-\delta}$ (LSM) by Fuel Cell Materials. $\mathrm{La}_{0.6} \mathrm{Sr}_{0.4} \mathrm{Co}_{0.2} \mathrm{Fe}_{0.8} \mathrm{O}_{3-\delta}$ (LSCF) was prepared by the Pechini synthesis method.

Chemical compatibility of the different electrode materials was tested by using X-ray diffraction (XRD) analysis of different mixtures: LSM, LNO and LSC after sintering together with BCZY27 at $1100{ }^{\circ} \mathrm{C}$ for $2 \mathrm{~h}$ and LSFC and BSFC after sintering with $\mathrm{BCZY} 27$ at $1000^{\circ} \mathrm{C}$ for $2 \mathrm{~h}$. XRD patterns were recorded in the $2 \theta$ range from 20 to $70^{\circ}$ on a CubiX FAST equipment using $\mathrm{CuK} \alpha_{1,2}$ radiation and an $\mathrm{X}^{\prime}$ Celerator detector in Bragg-Brentano geometry and patterns were analyzed using X'PertHighscore Plus software (PANalytical).

The microstructure was investigated using a field emission scanning electron microscopy (FE-SEM) (Zeiss Ultra 55), and the elemental analysis was carried out with energy-dispersive X-ray spectroscopy (EDS) (INCA, Oxford).

Commercial BCZY27 CerpoTech powder was used to prepare the electrolytes. Dense $\sim 1 \mathrm{~mm}$-thick BCZY disks were obtained by uniaxially pressing the powder at approximately $120 \mathrm{MPa}$ and firing at $1550{ }^{\circ} \mathrm{C}$ for $12 \mathrm{~h}$.

Cer-cer composites of the electrolyte and the different selected electrode materials were prepared by mixing $50 \mathrm{vol}$. \% of each phase and milling them together in an agate mortar. Inks for screen printing were prepared by using terpineol and ethylcellulose $(10 \%)$ in a roller mixer. Porous $30 \mu \mathrm{m}$-thick electrodes were obtained by screen printing the inks on both sides of the BCZY27 electrolyte. The sintering temperature of the electrodes was $1100{ }^{\circ} \mathrm{C}$ for LSM/BCZY27 and $1000{ }^{\circ} \mathrm{C}$ for LSCF/BCZY27 and $\mathrm{BSCF} / \mathrm{BCZY} 27$. The final symmetric button cell was $14.5 \mathrm{~mm}$ in diameter while the anodes were $9 \mathrm{~mm}$ in diameter approximately.

Finally, one LSCF/BCZY27 cer-cer electrode was optimized by changing the volumetric ratio of $\mathrm{LSCF}$ and $\mathrm{BCZY} 27$. Electrochemical performance of the different electrodes was investigated by preparing symmetric cells and by performing 
electrochemical impedance spectroscopy (EIS) measurements in a two-point/four wire configuration with platinum current collector meshes. Input signal was $0 \mathrm{~V} \mathrm{DC}-20 \mathrm{mV}$ $\mathrm{AC}$ in the $0.03-1 \cdot 10^{6} \mathrm{~Hz}$ frequency range (Autolab PGSTAT204 and PGSTAT128N potentiostats both equipped with a FRA32M module for impedance analysis). Raw impedance data were fitted to an equivalent circuit using Z-plot software. Electrode polarization resistances were measured from $800{ }^{\circ} \mathrm{C}$ to $500{ }^{\circ} \mathrm{C}$ under a total pressure of 3 bar (75\% steam in air). The pressure dependency on polarization resistance was investigated by varying the total pressure with constant oxygen to steam ratio $(75 \%$ steam, $25 \% \mathrm{O}_{2}$ ) and by varying $\mathrm{pO}_{2}$ or $p \mathrm{H}_{2} \mathrm{O}$ and allowing total pressure to vary proportionally. The flow was always kept constant at $100 \mathrm{~mL} \cdot \mathrm{min}^{-1}$.

\section{Results and discussion}

The chemical compatibility of the different selected electrode materials and the BCZY27 electrolyte was tested by means of XRD upon heat treatment. Figure 1 shows the XRD patterns of the LSM (a), LNO (b) and LSC (b) after sintering together with BCZY27 at $1100{ }^{\circ} \mathrm{C}$ for $2 \mathrm{~h}$ and the LSFC (c) and BSCF (d) after sintering with BCZY27 at $1000{ }^{\circ} \mathrm{C}$ for $2 \mathrm{~h}$. Furthermore, different reference patterns and starting material patterns are also included for comparison. It can be observed that while LSM, LSCF and BSCF are stable, with no extra peaks after the sintering process, LNO and LSC present some extra peaks as a result of reaction with the BCZY27 electrolyte phase. $\mathrm{LNO}$ gives rise to $\mathrm{Ce}_{6} \mathrm{O}_{11}$ and/or $\mathrm{BaO}$ segregation, while LSC favors the formation of $\mathrm{BaCrO}_{4}$. Thus, only LSM, LSCF and BSFC were further investigated in this study. 
(a) LSM: $\mathrm{La}_{0.8} \mathrm{Sr}_{0.2} \mathrm{MnO}_{3}$

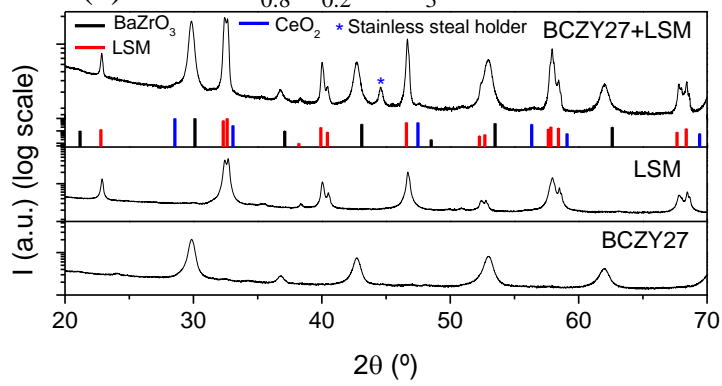

(c) LSC: $\mathrm{La}_{0.87} \mathrm{Sr}_{0.13} \mathrm{CrO}_{4}$

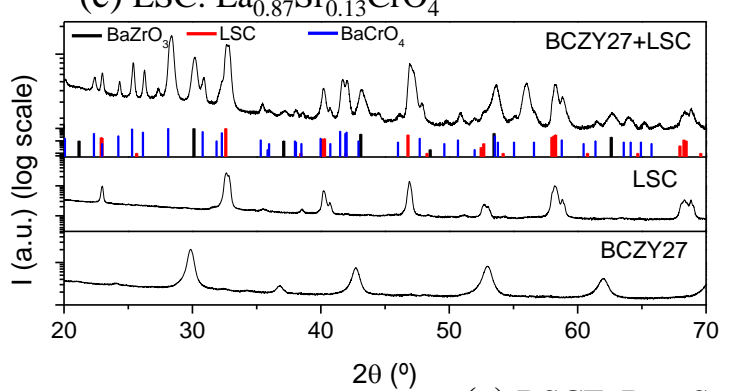

(b) LNO: $\mathrm{La}_{2} \mathrm{NiO}_{4}$

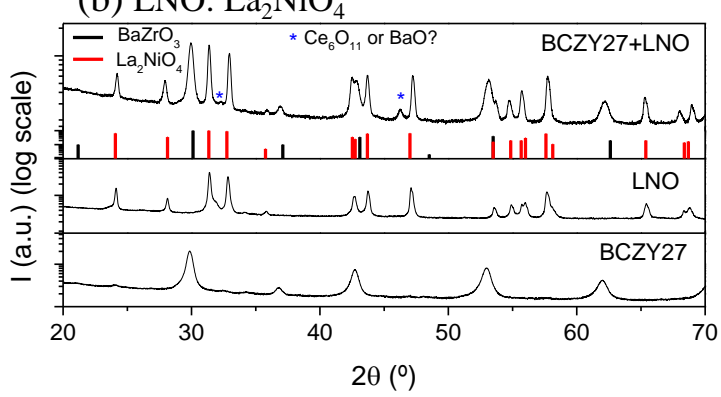

(d) LSFC: $\mathrm{La}_{0.6} \mathrm{Sr}_{0.4} \mathrm{Co}_{0.2} \mathrm{Fe}_{0.8} \mathrm{O}_{3}$

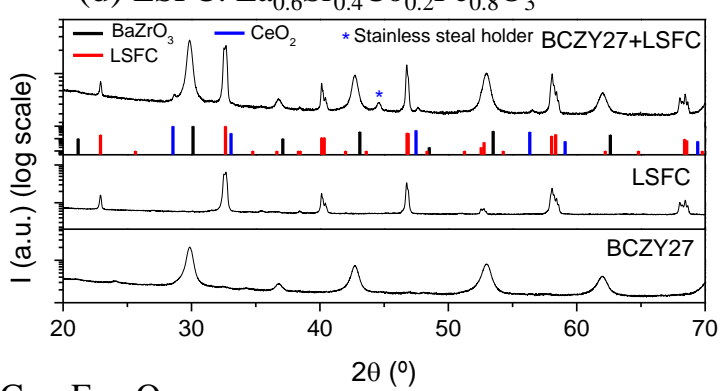

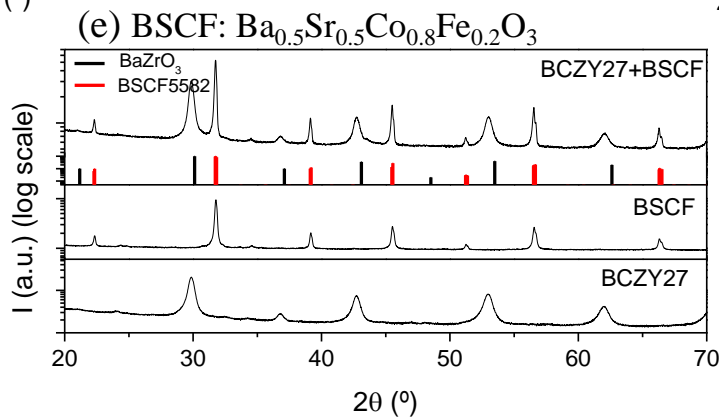

Figure 1. XRD patterns of the (a) LSM, (b) LNO and (c) LSC after sintering with BCZY27 at $1100{ }^{\circ} \mathrm{C}$ for $2 \mathrm{~h}$ and (d) LSFC and (e) BSFC after sintering with BCZY27 at $1000{ }^{\circ} \mathrm{C}$ for $2 \mathrm{~h}$.

The stability of BCZY27 with respect to LSM, LSFC and BSFC was also investigated under a total pressure of 3 bar, with a $25 \%$ air and $/ 75 \%$ (1.5 bar) of steam at $700{ }^{\circ} \mathrm{C}$ for $72 \mathrm{~h}$. XRD analysis (Figure 2) reveals that BSCF partially decomposed as can be deduced from the intensity decrease of the diffraction peaks and the appearance of some new phases (not identified). However, the other tested materials, i.e. BCZY27, LSM and LSFC, remained stable, with no extra diffraction peaks. There are slight changes in the diffraction peaks of LSCF, i.e., some double peaks becoming single and this is attributed to changes from orthorhombic to cubic symmetry. In summary, BCZY27, LSM and LSCF remained stable under electrolysis operation conditions, that is, high steam pressure, while the degradation of BSCF is expected under these conditions. 

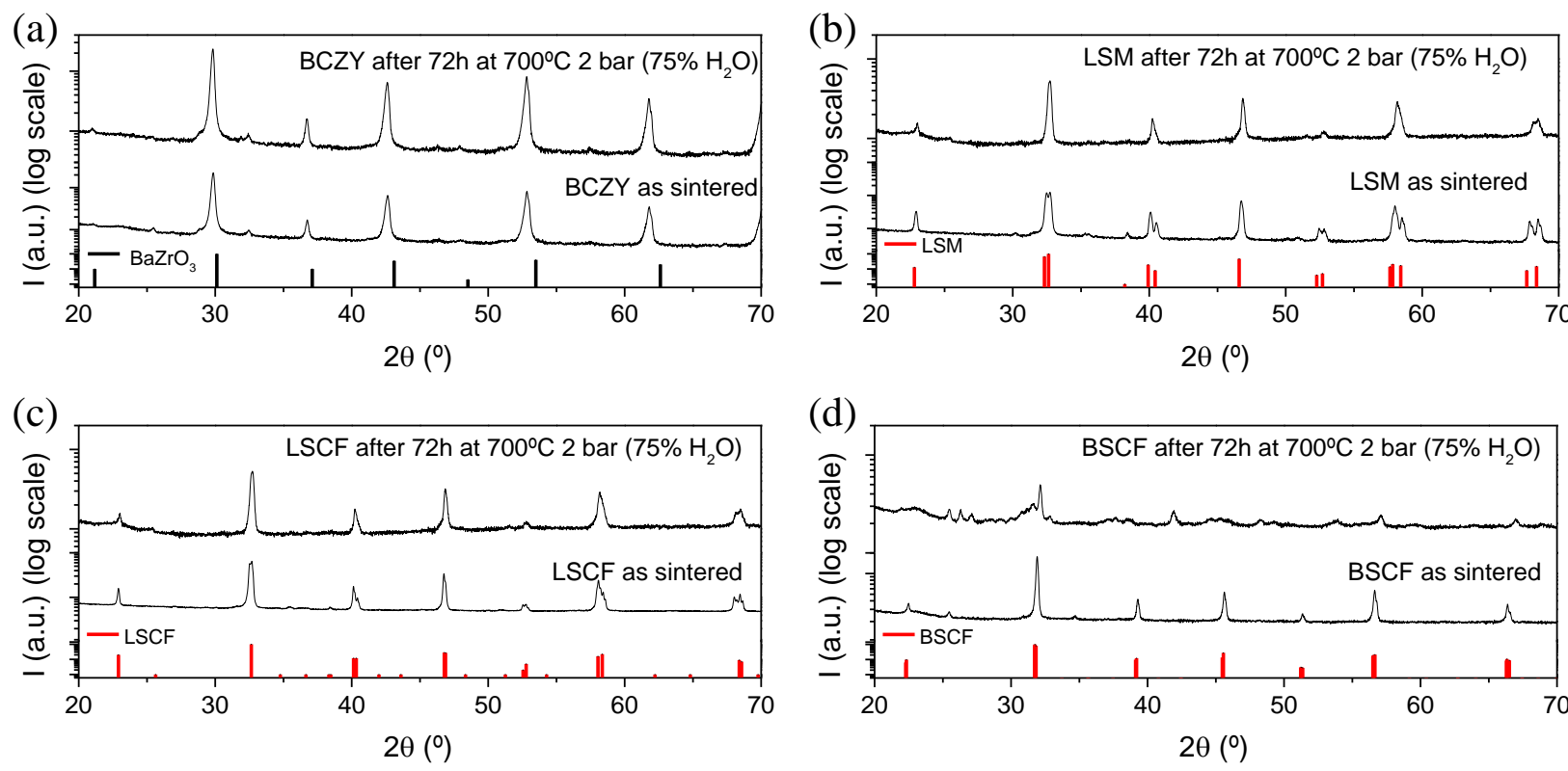

Figure 2. XRD patterns of the (a) BCZY27, (b) LSM, (c) LSCF and BSFC after being $72 \mathrm{~h}$ at $700^{\circ} \mathrm{C}$ under 3 bar of air with the $75 \%$ of steam (2.25 bar)

Polarization resistances $(\mathrm{Rp})$ of the three composite electrodes at 0.75 bar of air and 2.25 bar of steam are represented as a function of temperature in Figure 3. The highest $\mathrm{Rp}$ is observed for BSCF/BCZY27 electrode and this ascribed to the degradation under operation conditions (as shown in figure 2d). The LSM/BCZY27 electrode shows a slightly better performance at high temperatures, although around $100 \Omega \cdot \mathrm{cm}^{2}$ at $600{ }^{\circ} \mathrm{C}$. $\mathrm{R}_{\mathrm{p}}$ of LSCF/BCZY27 is by far the lowest of the three tested electrodes being 2 orders of magnitude lower than the one measured for other two, and reaching $0.1 \Omega \cdot \mathrm{cm}^{2}$ at 800 ${ }^{\circ} \mathrm{C}$. 


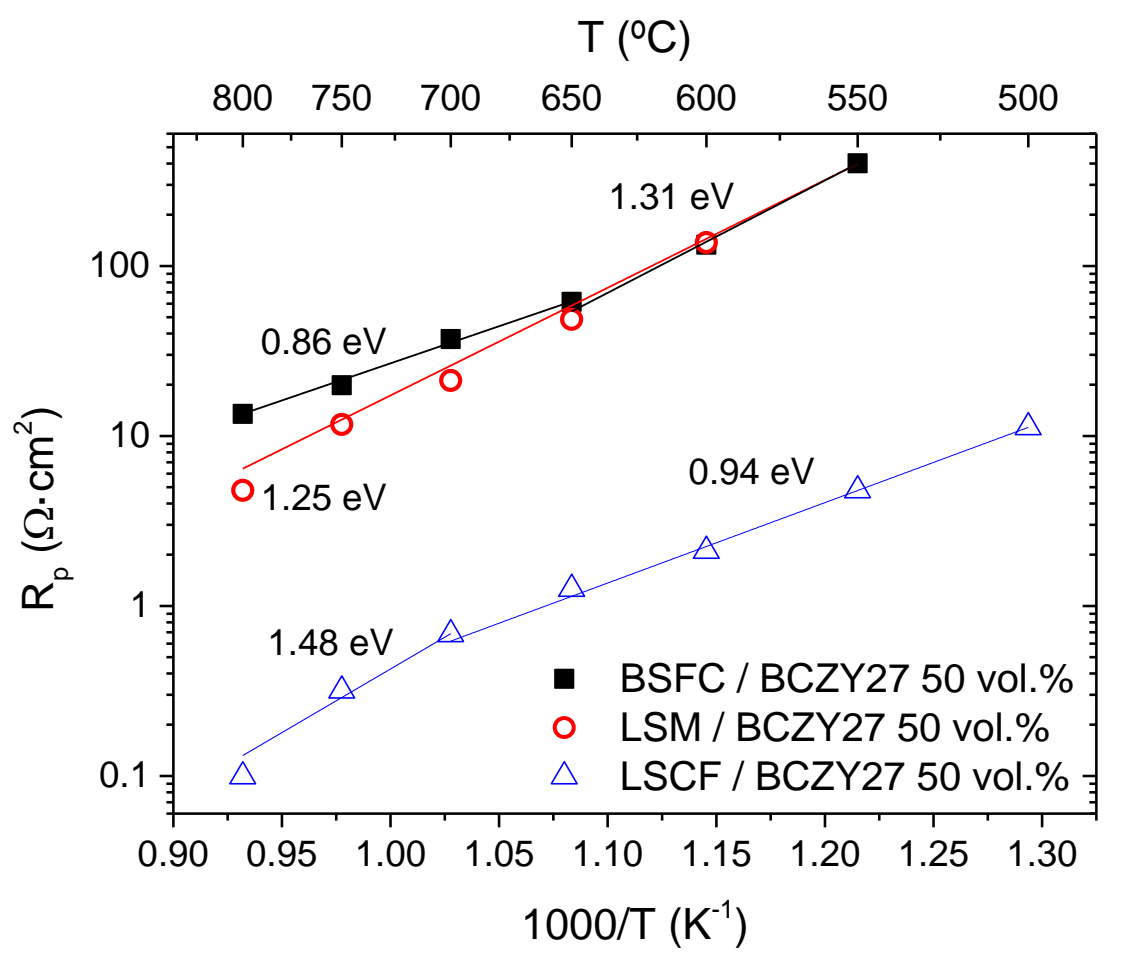

Figure 3. Temperature dependence of Rp for the three different tested electrodes

In order to identify the different mechanisms limiting the electrode operation and mostly contributing to $R_{p}$, impedance spectra were fitted by using equivalent circuits, slightly different for each type of electrode, which represent best the rate-limiting steps in each electrode. Specifically, The equivalent circuit $L\left(\mathrm{R}_{0} \mathrm{Q}_{0}\right)\left(\mathrm{R}_{M F} \mathrm{Q}_{M F}\right)\left(\mathrm{R}_{\mathrm{LF}} \mathrm{Q}_{L F}\right)$ was employed for the LSCF/BCZY (inset in Figure 4), $\mathrm{L}\left(\mathrm{R}_{0} \mathrm{Q}_{0}\right)\left(\mathrm{R}_{\mathrm{HF}} \mathrm{Q}_{\mathrm{HF}}\right)\left(\mathrm{R}_{\mathrm{LF}} \mathrm{Q}_{\mathrm{LF}}\right)$ for the $\mathrm{LSM} / \mathrm{BCZY}$ electrode and the equivalent circuit $\mathrm{L}\left(\mathrm{R}_{0} \mathrm{Q}_{0}\right)\left(\mathrm{R}_{\mathrm{HF}} \mathrm{Q}_{\mathrm{HF}}\right)\left(\mathrm{R}_{\mathrm{MF}} \mathrm{Q}_{\mathrm{MF}}\right)\left(\mathrm{R}_{\mathrm{LF}} \mathrm{Q}_{\mathrm{LF}}\right)$ for the BSCF/BCZY electrode. (inset in the supporting information, Figure S1). Figure 4 shows an example of the overall fit of the obtained results for the LSFC/BCZY27 electrode measured at $750{ }^{\circ} \mathrm{C}$ (circles are measured values, black line is fitting) and the different contributions to $\mathrm{R}_{\mathrm{p}}$. The different arcs were assigned to different reaction steps by the associated capacitance values $(\mathrm{C})$ obtained from each arc and the frequency rates. The first arc, with associated capacitance $\mathrm{C}_{0} \sim 5 \times 10^{-9} \mathrm{~F} / \mathrm{cm}^{2}$ and that takes place in the frequency range from $500 \mathrm{kHz}$ to $1 \mathrm{MHz}$, can be assigned to the electrolyte grain boundary[17] and does not contribute to the total Rp showed in Figure 3. Thus $\mathrm{R}_{\mathrm{MF}}$ and $\mathrm{R}_{\mathrm{LF}}$ are the electrode resistances, with associated capacitance of $\mathrm{C}_{\mathrm{MF}} \sim 1 \times 10^{-4} \mathrm{~F} / \mathrm{cm}^{2}$, which occurs at frequencies between 4 and $80 \mathrm{kHz}$ and $\mathrm{C}_{\mathrm{LF}} \sim 4 \mathrm{~F} / \mathrm{cm}^{2}$, in the frequency range between 1 and $30 \mathrm{~Hz}$. 
In general, for all the different tested electrodes the higher frequency (HF) semicircles can be assigned to a charge transfer reaction (e.g. transfer of protons between the electrolyte and the electrode), while the lower frequency (LF) semicircles, with higher associated capacitance values, can be ascribed to different elementary reactions on the surface, e.g., dissociative adsorption and diffusion of oxygen step.[16, 18-21]

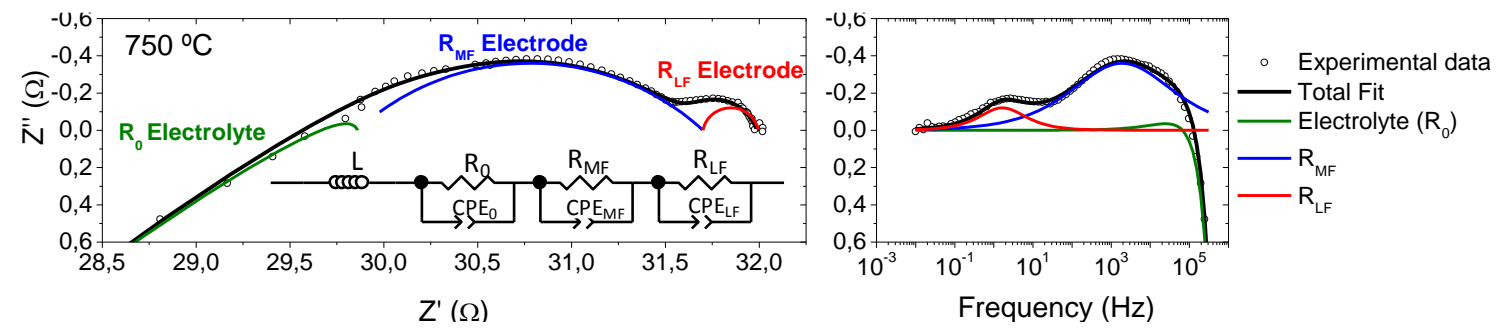

Figure 4. Impedance spectrum recorded for the LSCF/BCZY27 symmetric cell at $750{ }^{\circ} \mathrm{C}$ in air (steam pressure 2.25 bar). The symbols correspond to the experimental data and the solid lines to the fit using the shown equivalent circuit.
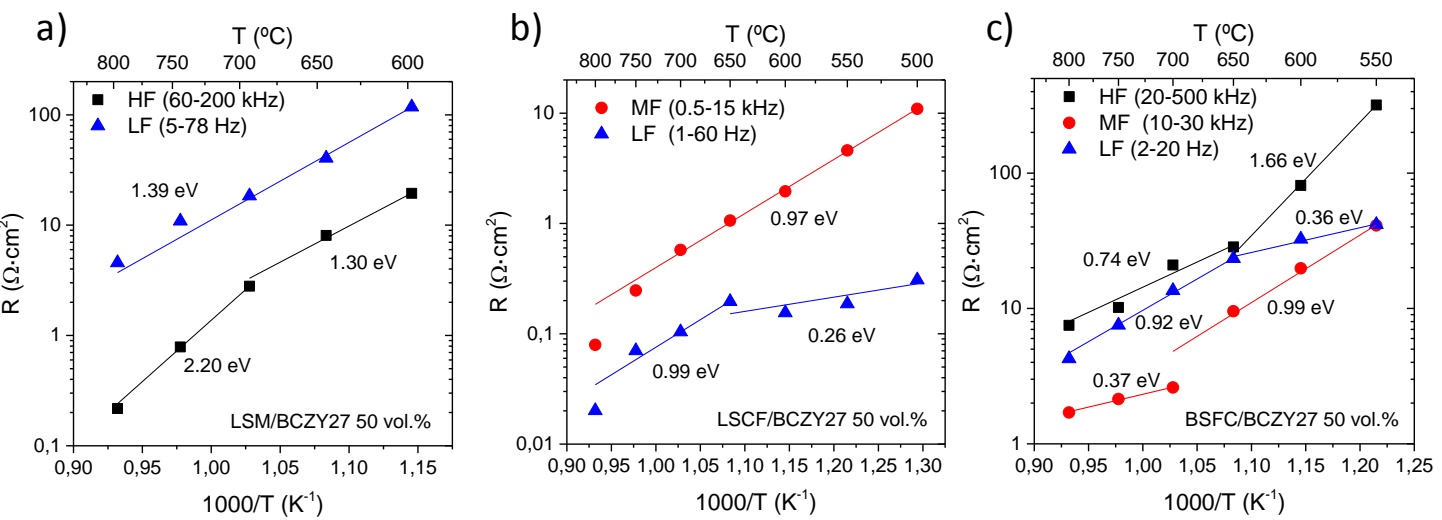

Figure 5. Temperature dependency of modelled resistances of LSM/BCZY27 50 vol.\% (a), LSCF/BCZY27 50 vol.\% (b) and BSCF/BCZY27 50 vol. \% (c) symmetric cells measured at 3 bar, $75 \%$ of steam in air.

Figure 5 presents partial polarization resistances as a function of temperature for the three tested electrodes. LSM/BCZY27 electrode has three different contributions and it is limited by LF surface-associated processes in the whole temperature range, displaying an activation energy $\left(\mathrm{E}_{\mathrm{A}}\right)$ value of $1.39 \mathrm{eV}$. The $\mathrm{HF}$ contribution, attributed to the charge transfer reaction, constitutes some $20 \%$ of the total $\mathrm{R}_{\mathrm{p}}$ and displays $\mathrm{E}_{\mathrm{A}}$ values of $2.2 \mathrm{eV}$ between 700 and $800{ }^{\circ} \mathrm{C}$ and $1.3 \mathrm{eV}$ between 500 and $700{ }^{\circ} \mathrm{C}$. This is well in line with previous reports based on LSM-composites on both protonic and oxide-ion conducting electrodes[5, 22, 23] although these values are significantly higher than those related to limiting process solely involving protons, e.g. $\mathrm{E}_{\mathrm{A}} \leq 0.6 \mathrm{eV}$. 
Therefore, this electrode appears to be limited by a surface process, impeded by the limited oxygen activation and water splitting electrocatalytic activity of LSM $[24,25]$. The activation energy of the rate determining LF process is in relatively good agreement with literature values.[26-29].

The LSCF/BCZY27 electrode performance is limited by contributions appearing at MF, especially at temperatures $650^{\circ} \mathrm{C}$. The LF process is not rate limiting and $\mathrm{R}_{\mathrm{LF}}$ is about twice lower than the MF resistance, although a change in the activation energy of the LF contribution is observed, which can be related to a change in the prevailing conduction mechanism in BCZY27 from oxide-ionic (high temperature) to protonic (lower temperature)[30, 31]. SEM analysis (Figure 6) of tested-cells cross-sections reveals that the electrode thickness is around 30-40 $\mu \mathrm{m}$ and the microstructure is highly porous. In the left-hand images of the three different cells, the interface between the composite electrode and the electrolyte of the symmetric cell is visible whereas in the following pictures the composite porous electrode can be observed at high magnification. 


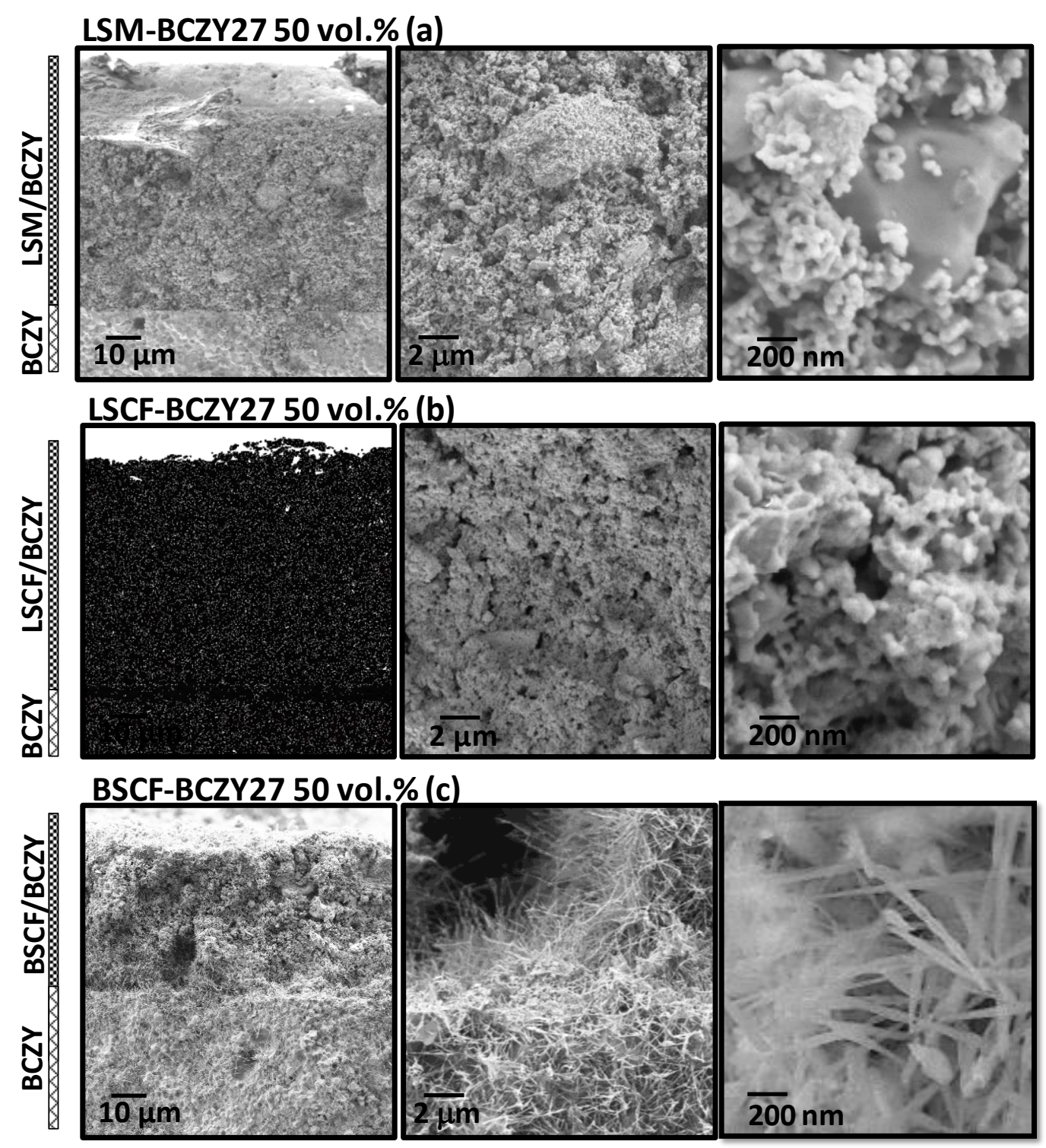

Figure 6. SEM micrographs of the fractured cross-section of LSM/BCZY27 (a), LSCF/BCZY27 (b) and $\mathrm{BSCF} / \mathrm{BCZY} 27$ (c)

In the images of the LSM/BCZY27 electrode (Figure 6a right-hand), the different components of the composite can be distinguished at higher magnification and the larger particles in the composite correspond to LSM. In LSCF/BCZY27 electrode (Figure 6b), the particle size of the two phases in the porous composite is very similar and thus the microstructure is optimized. In the case of BSCF/BCZY27 electrode, the exposure to steam causes the decomposition of the electrode material and formation of Ba-rich needle-like crystals all over the electrode surface (Figure $6 \mathrm{c}$ ).

The variation of vol. ratio of the different phases in the composite was studied for the best tested electrode, i.e. the LSCF/BCZY27 composite. Figure 7 a shows the temperature dependence of $R_{p}$ for three different electrodes with different phase 
compositions, LSCF/BCZY27 40/60, 50/50 and 60/40 vol. \% composites. The behavior of the three electrodes is similar and the best performance is observed for the 50/50 vol. $\%$ composite, as can be seen in Figure $7 \mathrm{~b}$ where $\mathrm{R}_{\mathrm{p}}$ at $700{ }^{\circ} \mathrm{C}$ is plotted as a function of the vol.\% of BCZY27 phase. Furthermore, this plot also shows the LF and MF resistance contributions and confirms that the MF process determine the electrode performance regardless of the BCZY27 vol. $\%$.
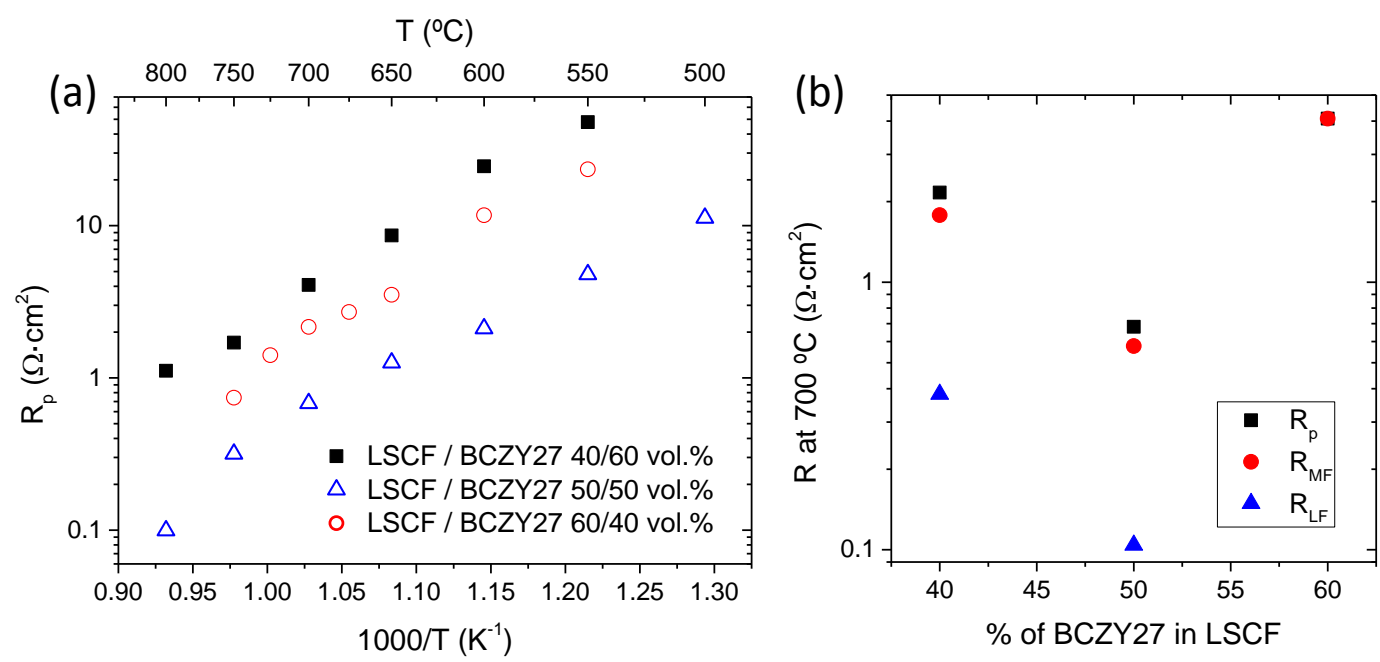

Figure 7. (a) Temperature dependence of $R_{p}$ for different tested electrodes with different phase compositions; and (b) $\mathrm{R}_{\mathrm{p}}$ and $\mathrm{R}_{\mathrm{LF}}$ and $\mathrm{R}_{\mathrm{MF}}$ contributions measured at $700{ }^{\circ} \mathrm{C}$ as a function of the vol\% of BCZY protonic phase introduced in the LSCF electrode

In order to further study the nature of the different resistance contributions, the best performing electrode (LSCF/BCZY27 50/50) (Figure 8) and the BCZY27 electrolyte material (Figure 9) were measured under different total pressures ( $\mathrm{p}_{\text {total }}$ ) and different $p \mathrm{O}_{2}$ and $p \mathrm{H}_{2} \mathrm{O}$ pressures (Figure 9). All data were obtained from the corresponding impedance spectra, i.e., electrode contributions values were obtained from the impedance fitting (arcs) and the electrolyte contribution from the cut with the $\mathrm{x}$-axis. Figure $8 \mathrm{a}$ shows total and partial $\mathrm{R}_{\mathrm{p}}$ as a function of the total pressure, when it changes from 1 to 6 bar, with a constant composition of steam (75\%) and air (25\%), thus both $p \mathrm{H}_{2} \mathrm{O}$ and $p \mathrm{O}_{2}$ vary proportionally (see the $p \mathrm{H}_{2} \mathrm{O}$ variation in the secondary top y-axis, that goes from 1.5 to 4.5 bar). While the LF resistance slightly increases until reaching a plateau, the MF resistance decreases linearly with increasing total pressure together with $p \mathrm{H}_{2} \mathrm{O}$. The corresponding EIS spectra can be observed in Figure S2 in Supporting Information. Figure 9a depicts the BCZY27 electrolyte conductivity extracted from the same impedance spectra. The conductivity increases with the total pressure (and $p \mathrm{O}_{2}$ 
and $p \mathrm{H}_{2} \mathrm{O}$ ), which can be ascribed to (i) higher proton conductivity, (ii) higher oxygenion conductivity and (iii) higher $p$-type electronic conductivity. It has previously been reported that BCZY27 exhibits p-type electronic and ionic carriers conduction at high temperatures and $p \mathrm{O}_{2} \cdot[7,32]$ Higher $p \mathrm{O}_{2}$ gives rise to higher $\mathrm{p}$-type and thus higher electrolyte conductivity and lower Rp. Indeed, $\mathrm{Rp}$ is both improved by higher $p \mathrm{O}_{2}$ and apparently lowered by the electron-leaky current. In addition, higher $p \mathrm{H}_{2} \mathrm{O}$ leads to higher total (proton) conductivity and possibly also a lower $\mathrm{Rp}$. Thus the decrease of $\mathrm{R}_{\mathrm{p}}$ with increasing total pressure can be ascribed to the increased $p$-type conduction induced by the higher $p \mathrm{O}_{2}$.

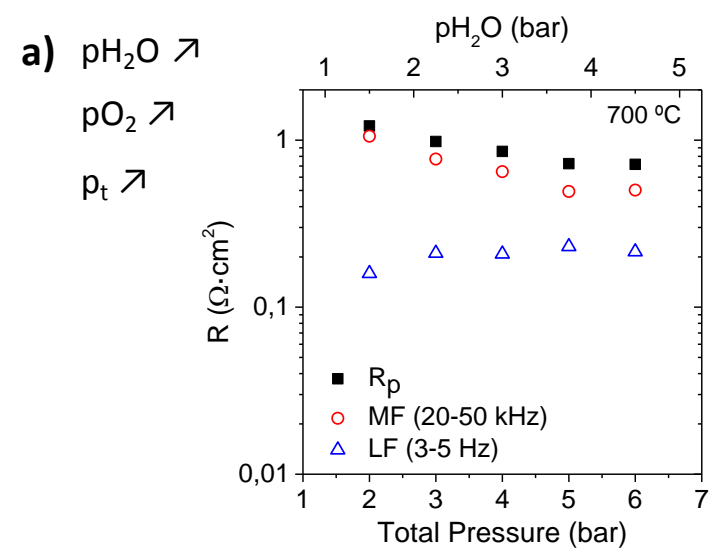

b) $\mathrm{pH}_{2} \mathrm{O} \rightarrow$ $\mathrm{pO}_{2} \nearrow$
$\mathrm{p}_{\mathrm{t}} \nearrow$

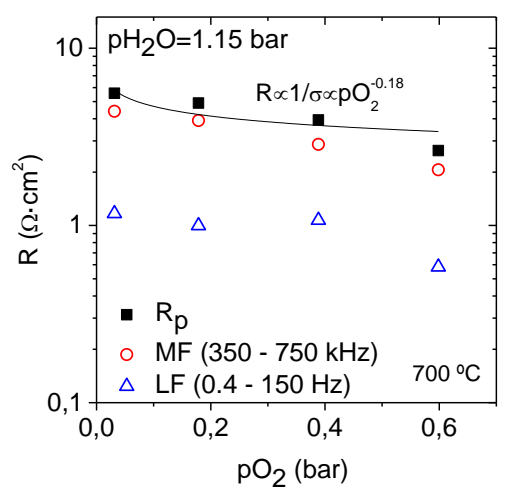

c) $\mathrm{pH}_{2} \mathrm{O} \lambda$ $\mathrm{pO}_{2} \rightarrow$

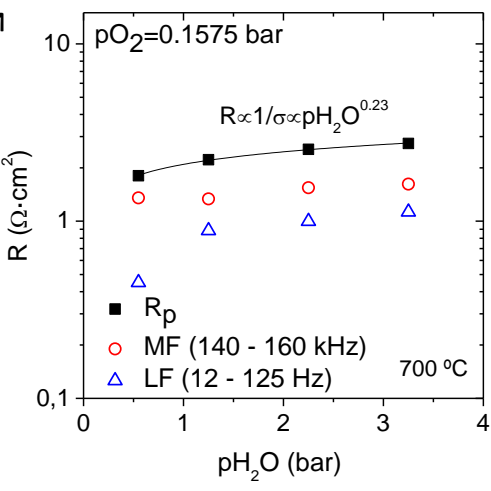

Figure 8. $R_{p}$ and MF and LF contributions at $700{ }^{\circ} \mathrm{C}$ as a function of: (a) total pressure with a constant $(75 \%)$ steam concentration (the total steam variation is also showed in the secondary top y-axis); (b) $p \mathrm{O}_{2}$ at constant $p \mathrm{H}_{2} \mathrm{O} \sim 1.15$ bar; and (c) $p \mathrm{H}_{2} \mathrm{O}$ at constant $p \mathrm{O}_{2} \sim 0.1575$ bar

Figure $8 b$ represents the isothermal analysis of $R_{p}$, and the $H F$ and $M F$ resistance contributions as a function of $p \mathrm{O}_{2}$ at constant $p \mathrm{H}_{2} \mathrm{O} \sim 1.15$ bar (thus the total pressure also increases). $\mathrm{R}_{\mathrm{p}}$ and all the different contributions decrease with increasing $p \mathrm{O}_{2}$ following a power law, $R_{p} \propto p O_{2}^{-0.18}$. The corresponding conductivity of BCZY27 electrolyte (Figure 9b) increases with increasing $p \mathrm{O}_{2}$ following a power law, $\sigma \propto$ $p O_{2}^{0.016}$. This small exponent is in contrast with the expected values $\left(1 / 6^{-1 / 4}\right)$ for $p$-type 
electronic conductor and reflects the importance of the ionic transport in this electrolyte under these oxidizing conditions.

Figure $8 c$ represents $\mathrm{R}_{\mathrm{p}}$ and the $\mathrm{HF}$ and MF contributions as a function of $p \mathrm{H}_{2} \mathrm{O}$ at constant $p \mathrm{O}_{2} \sim 0.1575$ bar. It can be observed that $\mathrm{R}_{\mathrm{p}}$ and both $\mathrm{HF}$ and MF contributions increase with $p \mathrm{H}_{2} \mathrm{O}$ following a power law, $\mathrm{R}_{p} \propto p \mathrm{H}_{2} \mathrm{O}^{0.23}$. This can be related to the fact that (1) p-type conduction is lowered and the $R_{p}$ is gradually less short-circuited by electron-leak current; and (2) the higher water gas concentration and surface coverage on the electrode impedes desorption and out-diffusion of the form $\mathrm{O}_{2}$ molecules. The corresponding conductivity of the electrolyte (Figure 9c) reveals a $p \mathrm{H}_{2} \mathrm{O}$ dependency following $\sigma \propto \mathrm{pH}_{2} \mathrm{O}^{0.043}$, significantly smaller than the expected $\mathrm{pH}_{2} \mathrm{O}^{0.5}$, that accounts for the hydration equilibrium, as the ideal behavior of a pure proton conductor. This smaller $p \mathrm{H}_{2} \mathrm{O}$ dependency can be related to possible processes (i) BCZY27 hydration starts approaching a saturation limit at $p \mathrm{H}_{2} \mathrm{O}>1$ bar and (ii) the decline in $\mathrm{p}$ type conduction as a consequence of the proton incorporation (oxide hydration) that involves the consumption of electron holes.
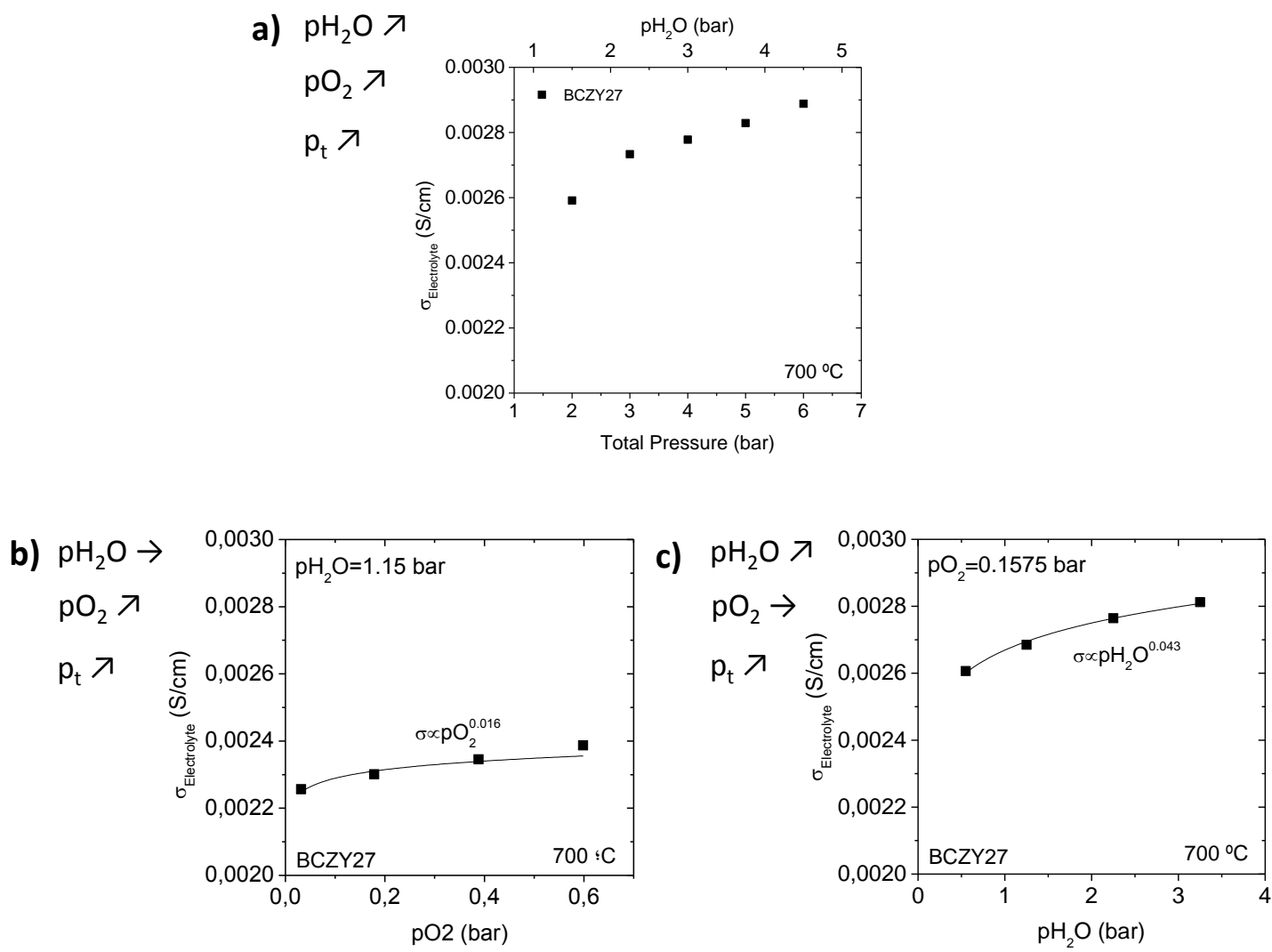

Figure 9. Total conductivity of the BCZY27 electrolyte as a function of: (a) total pressure at constant (75\%) steam concentration (the total steam variation is also showed in the top y-axis); (b) $p \mathrm{O}_{2}$ at constant $p \mathrm{H}_{2} \mathrm{O} \sim 1.15$ bar (c); and $p \mathrm{H}_{2} \mathrm{O}$ at constant $p \mathrm{O}_{2} \sim 0.5$ bar 


\section{Conclusions}

Five perovskite materials LSCF, LNO, LSC, LSM and BSCF were considered as potential steam electrodes for BCZY27 electrolysers. LSC and LNO were not compatible and react with BCZY27 electrolyte during electrode firing. LSCF and LSM remained stable under electrolysis conditions (3 bar, 25\% air, 75\% steam) while BSCF degraded to form Ba-rich needle-like phases.

Different ceramic-ceramic (cer-cer) composite electrodes were prepared by mixing 50 vol.\% of BSCF, LSCF and LSM materials and 50 vol.\% of BCZY27. These electrodes were tested as anodes on symmetric BCZY27 button cells in the temperature range 500$800{ }^{\circ} \mathrm{C}$ under electrolysis conditions.

The LSCF/BCZY27 composition was varied and the best performance is observed for the electrode with $50 / 50$ vol. ratio, reaching polarization resistances $<0.68 \Omega \cdot \mathrm{cm}^{2}$ at $700{ }^{\circ} \mathrm{C}$. The effect of both $p \mathrm{H}_{2} \mathrm{O}(0.4-3.2$ bar $)$ and $p \mathrm{O}_{2}(0.05-0.6$ bar $)$ was studied on the polarization resistance and BCZY27 conductivity. Increasing $p \mathrm{H}_{2} \mathrm{O}$ leads to a slight increase in the electrode polarization resistance $\left(\mathrm{R}_{\mathrm{p}}\right)$ while increasing and $p \mathrm{O}_{2}$ gives rise to a slight reduction in $\mathrm{R}_{\mathrm{p}}$. The electrolyte conductivity slightly increases with rising both $p \mathrm{H}_{2} \mathrm{O}$ and $p \mathrm{O}_{2}$.

\section{Acknowledgements}

Financial support by the Spanish Government (Grants SEV-2012-0267 and ENE2014-57651) and by the EU through FP7 Electra Project (Grant Agreement 621244) 


\section{SUPPORTING INFORMATION}

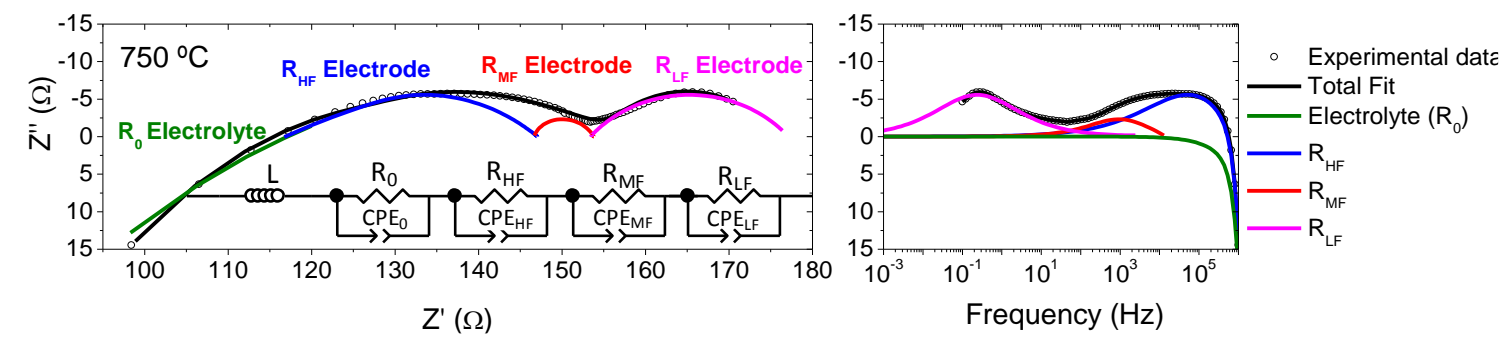

Supporting Figure S1: Impedance spectrum recorded for the BSCF/BCZY27 symmetric cell at $750{ }^{\circ} \mathrm{C}$ in air (steam pressure 2.25 bar). The symbols correspond to the experimental data and the solid lines to the fit using the shown equivalent circuit. 


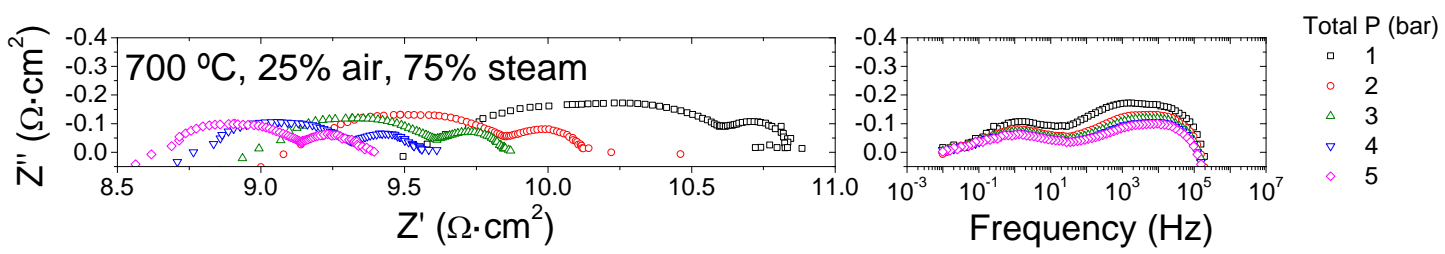

Supporting Figure S2: EIS spectra as a function of the total pressure at constant concentrations: $75 \%$ of steam and $25 \%$ of air 

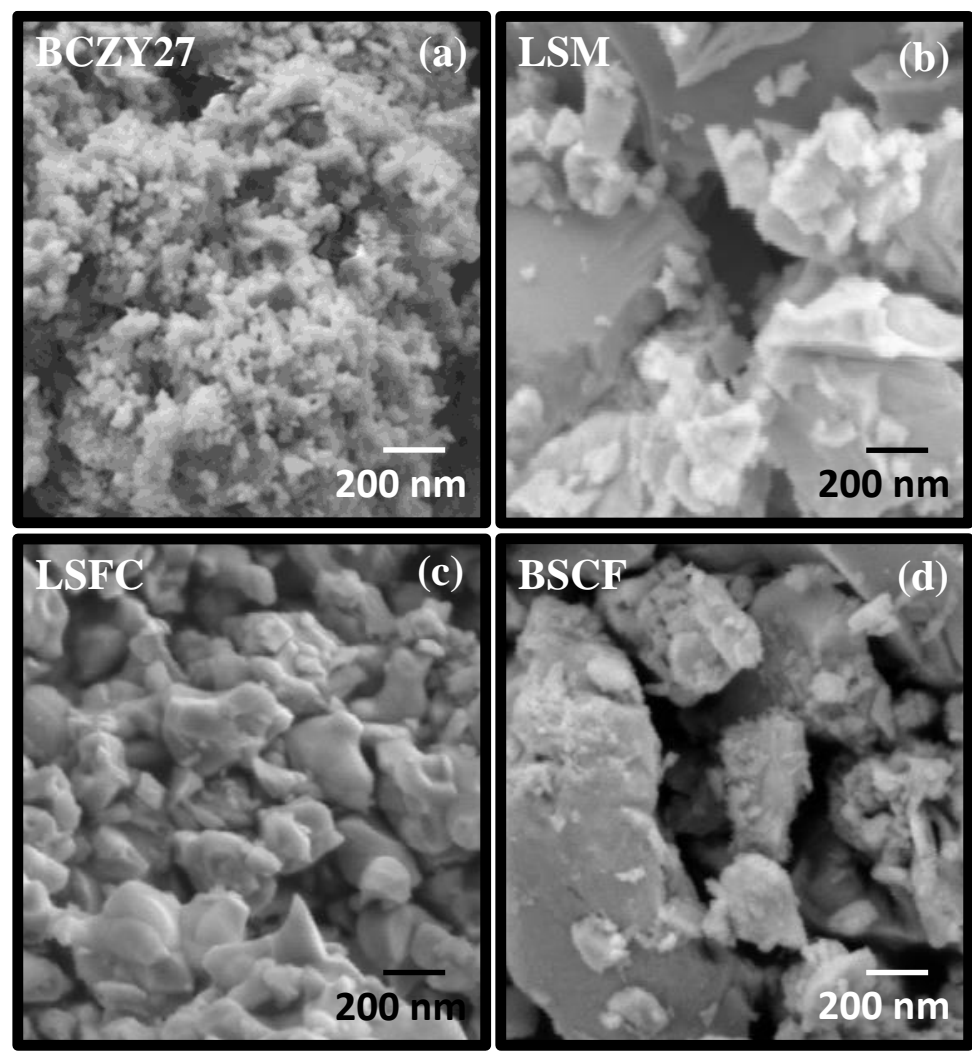

Supporting Figure S3: SEM micrographs of (a) BCZY27, (b) LSM, (c) LSFC and (d) BSCF materials used as starting powder for electrode preparation

The microstructure of the different powders used for the electrodes development can be observed in SEM images. The crystal size of the BCZY27 is very small (below $10 \mathrm{~nm}$ ) and only comparable to that of the LSFC phase (of around $50 \mathrm{~nm}$ ). However, LSM and BSCF present bigger particle sizes, between 200 and $600 \mathrm{~nm}$. 


\section{REFERENCES}

[1] H. Iwahara, Solid State Ionics 77 (1995) (0) 289.

[2] H. Iwahara, Y. Asakura, K. Katahira, M. Tanaka, Solid State Ionics 168 (2004) (3-4) 299.

[3] S. Escolástico, C. Solís, J.M. Serra, International Journal of Hydrogen Energy 36 (2011) (18) 11946.

[4] C. Solís, V.B. Vert, M. Fabuel, J.M. Serra, Journal of Power Sources 196 (2011) (22) 9220 .

[5] C. Solís, L. Navarrete, S. Roitsch, J.M. Serra, Journal of Materials Chemistry 22 (2012) (31) 16051.

[6] S. Escolastico, C. Solis, C. Kjolseth, J.M. Serra, Energy \& Environmental Science 7 (2014) (11) 3736.

[7] S. Escolástico, M. Ivanova, C. Solís, S. Roitsch, W.A. Meulenberg, J.M. Serra, RSC Advances 2 (2012) (11) 4932.

[8] Y. Yamazaki, R. Hernandez-Sanchez, S.M. Haile, Chemistry of Materials 21 (2009) (13) 2755.

[9] C. Duan, J. Tong, M. Shang, S. Nikodemski, M. Sanders, S. Ricote, A. Almansoori, R. O’Hayre, Science 349 (2015) (6254) 1321.

[10] L. Bi, S. Boulfrad, E. Traversa, Chemical Society Reviews 43 (2014) (24) 8255.

[11] M. Ni, M.K.H. Leung, D.Y.C. Leung, International Journal of Hydrogen Energy 33 (2008) (9) 2337.

[12] A. Brisse, J. Schefold, M. Zahid, International Journal of Hydrogen Energy 33 (2008) (20) 5375.

[13] H. Iwahara, H. Uchida, N. Maeda, Journal of Power Sources 7 (1982) (3) 293.

[14] K.D. Kreuer, Solid State Ionics 97 (1997) (1-4) 1.

[15] E. Stefan, T. Norby, Chemical Communications 52 (2016) (9) 1759.

[16] S. Ricote, N. Bonanos, P.M. Rorvik, C. Haavik, Journal of Power Sources 209 (2012) 172.

[17] J. Dailly, S. Fourcade, A. Largeteau, F. Mauvy, J.C. Grenier, M. Marrony, Electrochimica Acta 55 (2010) (20) 5847.

[18] S. Ricote, N. Bonanos, F. Lenrick, R. Wallenberg, Journal of Power Sources 218 (2012) 313.

[19] R. Peng, T. Wu, W. Liu, X. Liu, G. Meng, Journal of Materials Chemistry 20 (2010) (30) 6218.

[20] E. Fabbri, L. Bi, D. Pergolesi, E. Traversa, Energy \& Environmental Science 4 (2011) (12) 4984.

[21] C. Solis, L. Navarrete, S. Roitsch, J.M. Serra, Journal of Materials Chemistry 22 (2012) (31) 16051.

[22] L. Navarrete, C. Solis, J.M. Serra, Journal of Materials Chemistry A 3 (2015) (32) 16440. 
[23] C. Solis, L. Navarrete, F. Bozza, N. Bonanos, J.M. Serra, ChemElectroChem 2 (2015) (8) 1106.

[24] S.S. Li, R.Q. Yan, G.J. Wu, K. Xie, J.G. Cheng, International Journal of Hydrogen Energy 38 (2013) (35) 14943.

[25] L.Z. Gan, L.T. Ye, M.Z. Liu, S.W. Tao, K. Xie, Rsc Advances 6 (2016) (1) 641.

[26] E. Quarez, K.V. Kravchyk, O. Joubert, Solid State Ionics 216 (2012) 19.

[27] X.G. Cao, S.P. Jiang, International Journal of Hydrogen Energy 38 (2013) (5) 2421.

[28] Y.J. Leng, S.H. Chan, K.A. Khor, S.P. Jiang, Journal of Solid State Electrochemistry 10 (2006) (6) 339.

[29] E.P. Murray, T. Tsai, S.A. Barnett, Solid State Ionics 110 (1998) (3-4) 235.

[30] R. Strandbakke, V.A. Cherepanov, A.Y. Zuev, D.S. Tsvetkov, C. Argirusis, G. Sourkouni, S. Prunte, T. Norby, Solid State Ionics 278 (2015) 120.

[31] R. Strandbakke, E. Vøllestad, S.A. Robinson, M.-L. Fontaine, T. Norby, Journal of The Electrochemical Society 164 (2017) (4) F196.

[32] S. Ricote, N. Bonanos, H.J. Wang, R. Haugsrud, Solid State Ionics 185 (2011) (1) 11 . 